\title{
Yttria- Stabilized Tetragonal Zirconia with Superior Mechanical Properties Prepared Using Gel Casting Technology and a Two-Stage Sintering Process
}

Jing-Siang Jhan

National Cheng Kung University

Chih-Cheng Chen

Far East University

Yu-Chi Liu

National Cheng Kung University

Hsing-I Hsiang ( $\square$ hsingi@mail.ncku.edu.tw)

National Cheng Kung University https://orcid.org/0000-0001-7058-218X

\section{Research Article}

Keywords: Yttria-stabilized tetragonal zirconia (YTZP), Dolapix CE64, polymerization initiator,

hydroquinone

Posted Date: August 24th, 2021

DOI: https://doi.org/10.21203/rs.3.rs-809997/v1

License: (c) (i) This work is licensed under a Creative Commons Attribution 4.0 International License.

Read Full License 


\section{Abstract}

Yttria-stabilized tetragonal zirconia (YTZP) ceramics with high densification and superior mechanical properties were obtained using gel casting technology and a two-stage sintering process. Well-dispersed Nano-sized $(94 \mathrm{~nm})$ zirconia slurry with high solid content (45vol\%) was prepared for gel casting using Dolapix CE64 as the dispersant. As the dispersed slurry was added epoxy monomer (EGDGE) and polymerization initiator (DPTA), Dolapix CE64 promoted gelling, leading to an abrupt increase in the slurry viscosity. As Dolapix CE64 was added into the slurry, its functional carboxyl groups reacted with EGDGE, resulting in a decrease in gelling incubation time and an increase in viscosity, hence, leading to gel casting failure. The addition of hydroquinone $(\mathrm{HQ})$ into the slurry can be used to delay the polymerization and extend the gel casting working time. After gel casting, the temperature was raised to above $60^{\circ} \mathrm{C}$ to promote the polymerization, leading to an increase in the green strength.

A two-stage sintering process was used to control the grain growth. The first stage sintering temperature was chosen at $1300^{\circ} \mathrm{C}$, where the relative density reached $83 \%$. In the second sintering stage, the temperature was lowered to $1240^{\circ} \mathrm{C}$ and soaked for $24 \mathrm{~h}$ to inhibit grain growth (mean grain size of 195 $\mathrm{nm}$ ) and continue densification to a relative density of above $99 \%$. Vickers hardness of $15.2 \mathrm{GPa}$, fracture toughness of $7.8 \mathrm{MPa} \cdot \mathrm{m}^{1 / 2}$, and flexural strength of $771 \mathrm{MPa}$ can be obtained for the sample prepared using gel casting technology with a two-stage sintering process.

\section{Introduction}

Yttria stabilized zirconia (YTZP) has been widely used in industry. It has many benefits, such as high melting point, high chemical stability, high mechanical strength, high toughness, and high hardness (Mohs hardness 8.5, second only to diamond and corundum). Because of its excellent mechanical properties and wear resistance, YTZP is now widely used in the back-cover of mobile phones, thermal barriers, oxygen sensors, dental implants, and knee joint replacements [1-5].

The resistance to wear and abrasion of YTZP will be degraded with increasing grain size. YTZP ceramics with a small grain size have received much attention recently because they exhibit high hardness and good fracture toughness $[6,7]$.

However, the grain size of the sintered body is larger than that of the powders due to grain growth during sintering. Therefore, suppressing grain growth during sintering is a key factor in fabricating nanostructured materials. To achieve densification without significant grain growth, grain boundary diffusion must be maintained, while inhibiting grain boundary migration. It is well known that the solute drag [8] and two-stage sintering process $[9,10]$ are effective strategies to control grain growth in the final sintering step. However, it is difficult to find an effective dopant to control the microstructure for newly-developed ceramics. Two-stage sintering is an effective, simple, and economical microstructure refinement method, and hence has been widely used to obtain high-density bodies and smaller grain sizes. 
The ceramic forming methods can be classified into dry [11-13] and wet forming processes [14-17]. The wet forming processes, such as slip casting [14] and gel casting [15-17] have been used to prepare complex-shaped ceramics. For wet forming processes, the powder agglomeration problem can be solved by preparing well-dispersed slurry. However, the slip casting method has some drawbacks, such as the need for a plaster mold for dehydration, long molding time, and low green strength, and hence is not suitable for making thick sections. Gel-casting is a wet forming technology developed by the Oak Ridge National Laboratory (ORNL) that has the potential to manufacture high-density ceramics with complex shapes [15-16]. It has the benefits of short molding time, no mold material restriction, high green strength, and applicable to thick sections. Gel casting technology can be classified into solvent and aqueous systems. The solvent gel casting process is extensively used because it is easy to disperse due to the lower surface tension and difficulty to form bubbles. However, the aqueous gel casting process is cheaper and more environmentally friendly compared to the solvent system $[18,19]$. For aqueous-based gel-casting, the ceramic powder is first dispersed in water and then monomer and initiator are added and mixed to form a dispersed slurry, which is poured into the mold and polymerized at high temperature to form a green body with fewer defects, higher density, and better mechanical properties as compared to other alternatives. [20, 21]. For the wet-forming process, the slurry dispersion affects the green microstructure, and thereby the microstructure, mechanical strength, and optical properties of sintered ceramics.

To improve the mechanical properties of zirconia ceramics, aqueous gel casting and a two-stage sintering process combination was used in this study to prepare the well-densified YTZP ceramics with fine grain size. The well-dispersed slurry with high solid content is prepared first, and then an aqueous gel casting process is used to prepare homogeneous green bodies with high green density. A two-stage sintering process is used to facilitate densification with limited grain growth. Dolapix CE64 has been considered the most effective dispersant for aqueous zirconia slurry [22, 23]. However, Dolapix CE64 promoted gelling, leading to an abrupt increase in the slurry viscosity. As Dolapix CE64 is used in preparing YTZP aqueous slurry, its functional group reacts easily with the monomer, EGDGE, resulting in a decrease in the gelling incubation time and an increase in the viscosity, hence, leading to gel casting failure. However, no related study has been reported to our best knowledge. In this study, YTZP powder with an average particle size of $94 \mathrm{~nm}$ was used to prepare the slurry with a solid load of $45 \mathrm{vol} \%$ for the gel casting process and the different dispersants, solid content, and polymerization inhibitor effects on the dispersion and slurry gelling rate were investigated. The sintered YTZP ceramics with a sintered density of $99.4 \%$ and grain size of about $195 \mathrm{~nm}$ can be successfully prepared using the aqueous gel casting and two-stage sintering processes.

\section{Experimental Procedure}

In this study, 3mol\% yttria-stabilized zirconia (YTZP) powder with a mean particle size of $94 \mathrm{~nm}$ was used as the raw material to prepare the green body using an aqueous gel casting process. The different amounts of commercial dispersants, Darven 821A (Vanderbilt Minerals), Darven C (Vanderbilt Minerals), and Dolapix CE64 (Zschimmer \& Schwarz), were mixed with YTZP powder and deionized water by ball 
milling for $12 \mathrm{~h}$ to prepare the slurry. Dolapix CE64 has been used to disperse YTZP in suspensions of up to $50 \mathrm{vol} \%$ solid content. The epoxy resin, ethylene glycol diglycidyl ether (EGDGE, Sigma-Aldrich, Germany) with a molecular weight of $176 \mathrm{~g} / \mathrm{mol}$, acted as the monomer and a polyamine hardener, bis (3aminopropyl) amine (DPTA, Sigma-Aldrich, Germany) were used to consolidate the suspensions [17]. YTZP suspensions with solid contents of 40,45 , and $50 \mathrm{vol} \%$ were prepared by dispersing a calculated amount of YTZP powder and Dolapix CE64 into the distilled water. After ball-milling for $24 \mathrm{~h}$ using Y-TZP balls, $15 w t \%$ EGDGE and glycerol (EGDGE/glycerol $=6 / 4$ ) and Hydroquinone (HQ) acted as a polymerization inhibitor were added into the suspension and ball-milled for $24 \mathrm{~h}$ using Y-TZP balls. After adding $0.25 \mathrm{~mol} /$ eq of DPTA, the suspension was degassed in a vacuum desiccator for 5 minutes and then poured into a silicone mold $(\phi=50 \mathrm{~mm})$. Polymerization of the samples sealed by plastic wrap was performed at 30,45 , and $60^{\circ} \mathrm{C}$ for $6 \mathrm{~h}$. Drying was carried out at $60^{\circ} \mathrm{C}$ for $24 \mathrm{~h}$. After demolding, cold isostatic pressing (CIP) was used to compact the green body at $200 \mathrm{MPa}$. Binder burnout was performed at $500^{\circ} \mathrm{C}$ for $1 \mathrm{~h}$ at a heating rate of $1^{\circ} \mathrm{C} /$ minute. The two-stage sintering method was used to densify and control the grain growth. At the first step, the debindered sample was sintered at $1300^{\circ} \mathrm{C}$. It was then cooled down to the lower temperatures of $1240^{\circ} \mathrm{C}$ with a cooling rate of $50^{\circ} \mathrm{C} / \mathrm{min}$ and soaked for $24 \mathrm{~h}$.

The crystalline phase identification was determined using X-ray diffractometry (Dandong Fangyuan, DX2700, Sandong, China) with CuKa radiation. The rheological behaviors of the YTZP slurries added with different amounts of dispersants were measured using a rotational viscometer (DV2TLVTJO, Brookfield, USA). The YTZP slurry functional groups before and after polymerization were characterized by FTIR. The sintering temperature was determined using a dilatometer (NETZSCH, DIL 402C). The densities of the green bodies and sintered bodies were measured by Archimedes' method. The green and sintered microstructures were observed using scanning electron microscopy (SEM, SU-5000, Hitachi, Japan). The pore size distribution and porosity of green bodies were measured using a pore size distribution analyzer (ASAP2020, Micromeritics, USA). The hardness and fracture toughness evaluations were performed using Vickers indentation (MVK-H1, Akashi, Japan) at a 10N load. Flexural strength was determined with the 3point bending test (support span: $30 \mathrm{~mm}$; thickness: $3 \mathrm{~mm}$; width: $4 \mathrm{~mm}$ ) on bar specimens.

\section{Results And Discussion}

Figure 1 shows the rheological behaviors of YTZP slurries added with different amounts of dispersants. For the slurries added with Darven 821A and Darven C, the rheological behaviors exhibited shear thinning. The slurry viscosity was higher at low shear rates, attributed to the network structure resulting from Van der Waal's attraction between nano-sized YTZP particles. As the shear rate increased, the network structure was broken up by the shearing force, which led to a decrease in viscosity. Darven $\mathrm{C}$ exhibited the poorest dispersant performance. The viscosity of slurry added Darven $\mathrm{C}$ increased rapidly as the solid content was increased above $45 \mathrm{vol} \%$, and hence only the rheology behavior was measured for the slurry with a solid content of $40 \mathrm{vol} \%$. For the slurry added with Dolapix CE64, as the dispersant addition was increased to $0.2 \mathrm{wt} \%$, the dispersion was improved and the slurry rheological behavior became nearly Newtonian, indicating that the YTZP slurry was completely dispersed. As the dispersant addition was 
further increased to $0.3 \mathrm{wt} \%$, the slurry rheology increased slightly. Table 1 shows the slurry viscosity results compared with those reported in the literature $[22,24,25]$. It was found that zirconia slurries can be dispersed better under alkaline conditions. This is due to the isoelectric point (IEP) of zirconia being at about pH 7 [26]. Therefore, in alkaline conditions, the zirconia particles exhibit higher zeta potential, leading to greater electrostatic repulsion. Moreover, Dolapix CE64 can be completely dissociated at pH 10 and then adsorbed onto the powder surface, hence leading to greater electrostatic repulsion and lower viscosity [27]. Figure 2 shows the particle size distribution of YTZP slurry added with $0.2 w t \%$ Dolapix CE64. This indicates that YTZP powder in the slurry exhibited a narrow particle size distribution and the mean particle size $\left(d_{50}\right)$ was about $165 \mathrm{~nm}$ which is close to the primary particle size of $94 \mathrm{~nm}$. This confirms that Dolapix CE64 exhibits the best dispersant performance and well-dispersed YTZP slurry can be obtained after adding $0.2 \mathrm{wt} \%$ Dolapix CE64.

Table 1

Comparison of the slurry viscosity of the result with those reported in the literature.

\begin{tabular}{|c|c|c|c|c|c|}
\hline particle size & dispersant & solid content & $\mathrm{pH}$ & viscosity & reference \\
\hline $94 \mathrm{~nm}$ & Dolapix CE64 0.2 wt\% & 45 vol\% & 10 & $\begin{array}{l}0.24 \mathrm{~Pa} . \mathrm{s} \\
(\text { shear rate }=0.11 / \mathrm{s})\end{array}$ & this study \\
\hline $100 \mathrm{~nm}$ & $\begin{array}{l}\mathrm{NH}_{4} \mathrm{PAA} \\
1 \mathrm{wt} \%\end{array}$ & $\begin{array}{l}50 \mathrm{wt} \% \\
\approx 14.2 \mathrm{vol} \%\end{array}$ & 8 & $\begin{array}{l}\text { 4.5 Pa.s } \\
\text { (shear rate }=0.11 / \mathrm{s})\end{array}$ & [24] \\
\hline $100 \mathrm{~nm}$ & Dolapix CE64 0.5 wt\% & $\begin{array}{l}60 \mathrm{wt} \% \\
\approx 20 \mathrm{vol} \%\end{array}$ & 8 & $\begin{array}{l}\text { 7.5 Pa.s } \\
(\text { shear rate }=0.11 / \mathrm{s})\end{array}$ & [22] \\
\hline $95 \mathrm{~nm}$ & $\mathrm{NH}_{4} \mathrm{PAA}$ & 45 vol\% & 7.1 & $\begin{array}{l}\text { 7.5 Pa.s } \\
\text { (shear rate }=51 / \mathrm{s} \text { ) }\end{array}$ & [25] \\
\hline
\end{tabular}

Table II Relative green densities of the samples prepared by gel casting.

\begin{tabular}{|lll|}
\hline Sample & Relative density (\%) & Relative density after binder burnout (\%) \\
\hline Without CIP & 60.7 & 58.4 \\
\hline CIP & 65.5 & 62.5 \\
\hline
\end{tabular}

Figure 3 shows the solid content effect on the rheological behaviors of YTZP slurries with $0.2 \mathrm{wt} \%$ Dolapix CE64. All YTZP slurries exhibited shear-thinning behavior and the viscosity at a low shear rate increased significantly as the YTZP powder content was increased to $50 \mathrm{vol} \%$. At a low shear rate, the dissipation is governed by the rupture network structure. As the YTZP powder solid content was increased to $50 \mathrm{vol} \%$ the steric barriers built by the adsorbed Doplaix CE64 on the powder surface came into contact and interpenetrated, which resulted in network structure build-up and yield behavior. The strong network structure and high yield stress of the YTZP slurry do not satisfy the viscosity requirements for the gel- 
casting process and easily result in bridging flocculation. Therefore, suitable YTZP slurry solid content with $0.2 \mathrm{wt} \%$ Dolapix CE64 is $45 \mathrm{vol} \%$.

After preparing well-dispersed YTZP slurry, epoxy monomers (EGDGE), plasticizers (glycerol), and polymerization initiators (DPTA) for gel casting must be added subsequently. Figure 4 displays the effect of adding different organic vehicles on the YTZP slurry viscosity. The viscosity nearly remained unchanged at a low shear rate and decreased slightly at a high shear rate after adding glycerol and EGDGE, suggesting the slurry remained well-dispersed. However, when DPTA was added, the viscosity at a low shear rate increased nearly 10 times. This indicates that the well-dispersed slurry may react with DPTA simultaneously once adding DPTA, resulting in gel formation. This makes the slurry unable to be poured into the mold.

FTIR spectroscopy can be used to investigate the reaction time between the monomer, EGDGE, and initiator, DPTA, which is shown in Fig. 5. When EGDGE reacts with DPTA, the glycidyl groups and ether groups of EGDGE will decrease, but a new functional hydroxyl (-OH) group appears [28]. Compared with EGDGE, no significant intensity change in the peaks at $1250 \mathrm{~cm}^{-1}$ and $1120 \mathrm{~cm}^{-1}$ was observed and the $\mathrm{OH}$ functional group did not appear after EGDGE and DPTA mixing for 0-20 min. As the mixing time was prolonged to $30 \mathrm{~min}$, the glycidyl group peak was significantly weakened and the hydroxyl group appeared, indicating that polymerization started. Based on the above results, the polymerization incubation time is longer than 20 min, which is sufficient for gel casting.

Figure 6 shows the Dolapix CE64 addition effect on the polymerization rate measured by FTIR spectroscopy. It can be seen that an obvious hydroxyl peak appeared and the glycidyl group peak intensity significantly decreased immediately after mixing EGDGE, DPTA, and Dolapix CE64. The FTIR spectrum of the sample mixed for $20 \mathrm{~min}$ is similar to that of the immediately mixed sample. It suggests that the polymerization reaction has been completed immediately after mixing due to the Dolapix CE64 addition. The dispersant Dolapix CE64 contains many carboxyl groups [22]. The glycidyl group base catalysis reaction with the carboxyl groups proceed at low temperature [29], which leads to the slurry exhibiting limited stability at room temperature.

Figure 7 shows the $\mathrm{HQ}$ addition effect on the polymerization rate measured by FTIR spectroscopy. When $\mathrm{HQ}$ was added into the EGDGE, DPTA, and Dolapix CE64 mixture for 30 min, no significant intensity change in the peaks at $1250 \mathrm{~cm}^{-1}$ and $1120 \mathrm{~cm}^{-1}$ was observed and the $\mathrm{OH}$ functional group did not appear; indicating that polymerization had not occurred. This means that HQ can improve the slurry stability and extend the gel casting working time to more than 30 minutes, which is helpful for the subsequent molding process. Figure 8 shows the effects of different curing temperatures and soaking time on the slurry viscosity (the mixture of EGDGE, DPTA, HQ, and Dolapix CE64). The slurry viscosity remained nearly unchanged for a long time at $30^{\circ} \mathrm{C}$, indicating the slurry exhibited good stability. When the temperature was raised to $45^{\circ} \mathrm{C}$ and $60^{\circ} \mathrm{C}$, a significant increase in viscosity was found for $200 \mathrm{~s}$ and $20 \mathrm{~s}$, respectively, indicating that gelation occurred. Figure 9 shows the appearance of gel-casted samples after curing at $45^{\circ} \mathrm{C}$ and $60^{\circ} \mathrm{C}$. After curing at $45^{\circ} \mathrm{C}$, some cracks were observed due to the poor green 
strength resulting from insufficient gelation. On the contrary, the sample cured at $60^{\circ} \mathrm{C}$ exhibited high green strength that can withstand severe volume shrinkage during dehydration without cracks.

The main organic vehicle in the slurry is monomers and plasticizers. The role of the monomer, EGDGE, in the slurry is to increase the green strength through the polymerization to become a binder. The function of the plasticizer, glycerol, is to allow the green body to be plastic, so that plasticizer can be a great aid in avoiding cracking by promoting plastic deformation. Cracks are thereby reduced during drying. In addition, glycerol can also reduce the glass transition temperature of the epoxy resin, which is beneficial to the increase in green density by promoting plastic deformation during CIP. Figure 10 shows the appearance of the gel-casted samples with different B/P ratios (binder/plasticizer ratio). It can be seen that many cracks occurred for the green body with a B/P ratio of 5:5 due to insufficient green strength during drying. On the other hand, the green body with a B/P ratio of $6: 4$ shrank uniformly and can be demolded smoothly without cracks because the green body had enough strength to withstand the huge volume shrinkage during drying.

Table II shows the relative green densities of the samples prepared by gel casting. The green density of the sample prepared by gel casting can reach more than $60 \%$ and about $58 \%$ after binder burnout. The green density of the gel-casted sample after CIP can further reach a relative density of $65.5 \%$ and $62.5 \%$ after binder burnout. Figure 11 shows the SEM microstructure of the green body prepared by gel casting and the CIP process. It can be seen that no large inter-agglomerate pore was observed, indicating the green body exhibited a homogeneous green microstructure. It reveals that the green body with a high density can be obtained by gel casting of a well-dispersed slurry and the plasticizer, glycerol, promoted the plastic deformation during CIP, leading to a higher green density, which will be beneficial to the densification.

Figure 12 shows the variation in shrinkage and instantaneous relative density with temperature for the YTZP green body. The two-stage sintering method was used to control the grain growth. Based on the dilatometry results, the first stage sintering temperature was chosen at $1300^{\circ} \mathrm{C}$, where the relative density reached $83 \%$, indicating that YTZP has reached the final stage of sintering. In the second sintering stage, the temperature was lowered to $1240^{\circ} \mathrm{C}$ and soaked for $24 \mathrm{~h}$ to inhibit the grain growth and continue densification. Figure 13 shows the SEM microstructures of the YTZP ceramic fracture surface after twostage sintering (first stage sintering temperature: $1300^{\circ} \mathrm{C}$, the second stage sintering: $1240^{\circ} \mathrm{C}$ for $24 \mathrm{~h}$ ). For the sample after two-stage sintering, the relative sintered density was $99.4 \%$, the mean grain size was 195 nm (Fig. 14) and nearly no inter-granular pores were found. This suggests that two-stage sintering can simultaneously inhibit grain growth, and promote densification.

Figure 15 shows the YTZP ceramic XRD pattern after two-stage sintering. It indicates that a large amount of metastable tetragonal phase remained after high-temperature sintering and cooling to room temperature. The crystalline phase that existed in YTZP ceramics after two-stage sintering was $92.3 \%$ tetragonal phase and $7.7 \%$ monoclinic phase. 
The average flexural strength, Vickers hardness, and fracture toughness $\left(\mathrm{K}_{\mathrm{IC}}\right)$ of the YTZP ceramics after two-stage sintering can reach $771 \pm 210 \mathrm{MPa}, 15.2 \pm 0.3 \mathrm{GPa}$, and $7.80 \pm 1.63 \mathrm{MPa} \cdot \mathrm{m}^{1 / 2}$, respectively. The Vickers hardness and flexural strength strongly depended on porosity and grain size, obeying Hall-Petch law [30-32] for dense ceramics with high densities (>99\%). It has been reported that grain boundaries can serve as the main obstacles for dislocation motion during deformation, and hence increase the hardness with decreasing grain size as a consequence of increasing grain boundary density [33]. Therefore, the YTZP ceramics prepared by the gel casting and two-stage sintering process exhibited superior hardness and fracture strength due to the high sintered density, small grain size, and homogeneous microstructure.

It is well known that YTZ ceramics have little monoclinic phase, exhibiting higher fracture strength than that with a $100 \%$ tetragonal phase [34]. The presence of a small amount of monoclinic phase in YTZP ceramics indicates that the tetragonal phase is relatively unstable and tends to transform into a monoclinic phase. During crack propagation, the tetragonal phase can transform into the monoclinic form due to tetragonal phase destabilization resulting from the large tensile stresses around a crack. The high fracture toughness for the YTZP ceramics may be attributed to tetragonal-to-monoclinic phase transformation constraint and its easy release during crack propagation. These results suggest that the combination of gel casting technology and two-stage sintering process can be a good candidate for preparing YTZP ceramics with complex shapes and superior mechanical properties.

\section{Conclusions}

The well-dispersed and high solid content (45 vol\%) YTZP slurry can be obtained after adding $0.2 \mathrm{wt} \%$ Dolapix CE64. The glycidyl group base catalysis reaction with Dolapix CE64 carboxyl groups proceeds at low temperature, which leads to the slurry exhibiting limited stability at room temperature. When HQ was added into the EGDGE, DPTA, and Dolapix CE64 mixture, the slurry stability can be improved and the gel casting working time was extended to more than 30 minutes, which is helpful for the subsequent molding process. A green body with high density can be obtained by gel casting well-dispersed YTZP slurry with the plasticizer, glycerol. This promotes plastic deformation during $\mathrm{CIP}$, leading to a high green density (65.5\%). YTZP ceramics with a relative sintered density of $99.4 \%$ and mean grain size of $195 \mathrm{~nm}$ can be obtained using two-stage sintering. The average flexural strength, Vickers hardness, and fracture toughness $\left(\mathrm{K}_{\mathrm{IC}}\right)$ of the YTZP ceramics after two-stage sintering can reach $771 \pm 210 \mathrm{MPa}, 15.2 \pm 0.3 \mathrm{GPa}$, and $7.80 \pm 1.63 \mathrm{MPa} . \mathrm{m}^{1 / 2}$, respectively. This suggests that the combination of gel casting technology and two-stage sintering process can be a good candidate to prepare YTZP ceramics with complex shapes and superior mechanical properties.

\section{Declarations}

\section{Acknowledgment}


This work was supported by the Ministry of Science and Technology, Taiwan (109-2622-E-269 -002 -CC3). The authors gratefully acknowledge the use of EM000600 of MOST108-2732-M-006-001 belonging to the Core Facility Center of National Cheng Kung University.

\section{References}

1. N. Mahato, A. Banerjee, A. Gupta, S. Omar, K. Balani, Progress in material selection for solid oxide fuel cell technology: a review. Progress Mater Sci. 72 (2015) 141-337.

2. D. Panthi, N. Hedayat, Y.H. Du, Densification behavior of yttria-stabilized zirconia powders for solid oxide fuel cell electrolytes. J. Adv. Ceram, 7 (2018) 325-335.

3. H. Lv, J. Bao, F. Ruan, F. Zhou, Q. Wang, W. Zhang, W. Guo, Y. Zhang, X. Song, S. An, Preparation and properties of black Ti-doped zirconia ceramics, J. Mater. Res. Tech. 9 (2020) 6201-6208.

4. S.M. Fathy, W. Al-Zordk, M.E. Grawish, M.V. Swain, Flexural strength and translucency characterization of aesthetic monolithic zirconia and relevance to clinical indications: A systematic review, Dent. Mater. 37 (2021) 711-730.

5. M.N. Rahaman, A.H. Yao, B.S. Bal, J.P. Garino, M.D. Ries, Ceramics for prosthetic hip and knee joint replacement, J. Am. Ceram. Soc. 90 (2007)1965-1988.

6. A.G. Evans, E. A. Charles, Fracture toughness determinations by indentation. J. Am. Ceram. Soc. 59 (1976) 371-372.

7. M.V. Swain, Grain-size dependence of toughness and transformability of $2 \mathrm{~mol} \% \mathrm{Y}$-TZP ceramics. J. Mater. Sci. Lett. 5 (1986)1159-1162.

8. K. Matsui, H. Yoshida, Y. Ikuhara, Review: microstructure-development mechanism during sintering in polycrystalline zirconia, Inter. Mater. Rev. 63 (2018) 375-406.

9. I.W. Chen, X.H. Wang, Sintering dense nanocrystalline ceramics without final-stage grain growth, Nature, 404 (2000) 168.

10. X.H. Wang, P.L. Chen, I.W. Chen, Two-step sintering of ceramics with constant grain-size, I. $\mathrm{Y}_{2} \mathrm{O}_{3}$. J. Am. Ceram. Soc. 89 (2006) 431-437.

11. J.W. Drazin, J.A. Wollmershauser, H. Ryou, M.A. Wolak, E.P. Gorzkowski, Pressureless low temperature sintering of nanocrystalline zirconia ceramics via dry powder processing, J. Am. Ceram. Soc. 103 (2020) 60-69.

12. K. Furuya, S. Takemoto, S. Yamashita, H. Sekine, Y. Yajima, M. Yoshinari, Low-temperature degradation of high-strength Y-TZP (yttria-stabilized tetragonal zirconia polycrystal), Dent. Mater. J. 39 (2020) 577-586.

13. A. Flaureau, A. Weibel, G. Chevallier, C. Estournes, Study of the densification and grain growth mechanisms occurring during spark plasma sintering of different submicronic yttria-stabilized zirconia powders, J. Europ. Ceram. Soc. 41 (2021) 3581-3594.

14. D.S. Kim, W.C. Kim, J.K. Lee, Effect of solid loading on the sintered properties of $3 \mathrm{~mol} \%$ yttriastabilized tetragonal zirconia polycrystals (3Y-TZP) ceramics via slip casting, J. Nanosci. Naonotech. 
19 (2019) 6383-6386.

15. A.C. Young, O.O. Omatete, M. A. Janney, P. A. Menchhofer, Gelcasting of alumina. J. Am. Ceram. Soc. 74 (1991) 612-618.

16. M. A. Janney, O.O. Omatete, C. A.Walls, S. D. Nunn, R. J. Ogle, G. Westmoreland, Development of lowtoxicity gelcasting systems. J. Am. Ceram. Soc. 81 (1998) 581-591.

17. K. Y. Lee, C. C. Chen, H. I. Hsiang, F. S. Yen, C. Y. Huang, Fully sintered alumina with a higher Vickers hardness prepared using a gel-casting process, Int. J. Appl. Ceram. Technol. 16 (2019) 1493-1500.

18. X.G. Liu, G.J. Li, J.F. Tong, D.M. Chen, Low-cost fabrication for $\mathrm{ZrO}_{2}$-based electrolyte thin-substrate by aqueous gel-casting, J. Rare Earths 22 (2004) 514-516.

19. X.G. Liu, D.M. Chen, G.J. Li, J.F. Tong, Y. Zhou, L.H. Du, B.T. Li, An low cost preparation of aqueous gel-casting of YSZ solid electrolyte, Rare Met. Mater Eng. 31 (2002) 225-228.

20. A. Krell, J. Klimke, T. Hutzler, Advanced spinel and sub- $\mu \mathrm{m} \mathrm{Al}_{2} \mathrm{O}_{3}$ for transparent armour applications, J. Eur. Ceram. Soc. 29 (2009) 275-281.

21. Y. Sun, X. Qin, G. Zhou, H. Zhang, X. Peng, S. Wang, Gelcasting and reactive sintering of sheet-like YAG transparent ceramics, J. Alloys Compd. 652 (2015) 250-253.

22. S. P. Rao, S. S. Tripathy, A.M. Raichur, Dispersion studies of sub-micron zirconia using Dolapix CE 64, Colloids Surf. A Physicochem. Eng. Asp. 302 (2007) 553-558.

23. I. Rodrigues, M. Guedes, S. Olhero, A. Chefdor, A.C. Branco, M. Leite, A.P. Serro, C.G. Figueiredo-Pina, Development of free binder zirconia-based pastes for the production of dental pieces by robocasting, J. Manuf. Process. 57 (2020) 1-9.

24. Z. Xie, J. Ma, Q. Xu, Y. Huang, Y.B. Cheng, Effects of dispersants and soluble counter-ions on aqueous dispersibility of nano-sized zirconia powder, Ceram. Inter. 30 (2004) 219-224.

25. D.M. Liu, Rheology of aqueous suspensions containing highly concentrated nano-sized zirconia powders, J. Mater. Sci. Lett. 17 (1998) 1883-1885.

26. F. Tang, X. Huang, Y. Zhang, J. Guo, Effect of dispersants on surface chemical properties of nanozirconia suspensions. Ceram. Inter. 26 (2000) 93-97.

27. H. Sarraf, A. Sabet, R. Herbig, J. Havrda, V. Hulinsky, M. Maryska, Advanced colloidal techniques for characterization of the effect of electrosteric dispersant on the colloidal stability of nanocrystalline $\mathrm{ZrO}_{2}$ suspension, J. Ceram. Soc. Jap. 117 (2009) 302-307.

28. R. Xie, K. Zhou, X. Gan, D. Zhang, Effects of epoxy resin on gelcasting process and mechanical properties of alumina ceramics. J. Am. Ceram. Soc. 96 (2013) 1107-1112.

29. W.J. Blank, Z.A. He, M. Picci, Catalysis of the epoxy-carboxyl reaction, J. Coat. Technol.74 (2002) 3341.

30. X. Zhang, S. Liang, H. Li, J. Yang, Mechanical and optical properties of transparent alumina obtained by rapid vacuum sintering, Ceram. Int. 43 (2017) 420-426.

31. A. Krell, P. Blank, Grain Size Dependence of Hardness in Dense Submicrometer Alumina, J. Am. Ceram. Soc. 78 (1995) 1118-1120. 
32. C.S. Pande, K.P. Cooper, Nanomechanics of Hall-Petch relationship in nanocrystalline materials, Progress in Materials Science 54 (2009) 689-706.

33. R.W. Rice, C.C. Wu, F. Borchel, Hardness-grain-size relations in ceramics, J. Am. Ceram. Soc. 77 (1994) 3539-3553.

34. J. Chevalier, L. Gremillard, A.V. Virkar, D.R. Clarke, The tetragonal-monoclinic transformation in zirconia: lessons learned and future trends, J. Am. Ceram. Soc. 92 (2009) 1901-1920.

Figures 



Figure 1

Rheological behaviors of the YTZP slurries added with different amounts of dispersants (Darven 821A: D821A; Darven C: D-c; Dolapix CE64: CE64). 


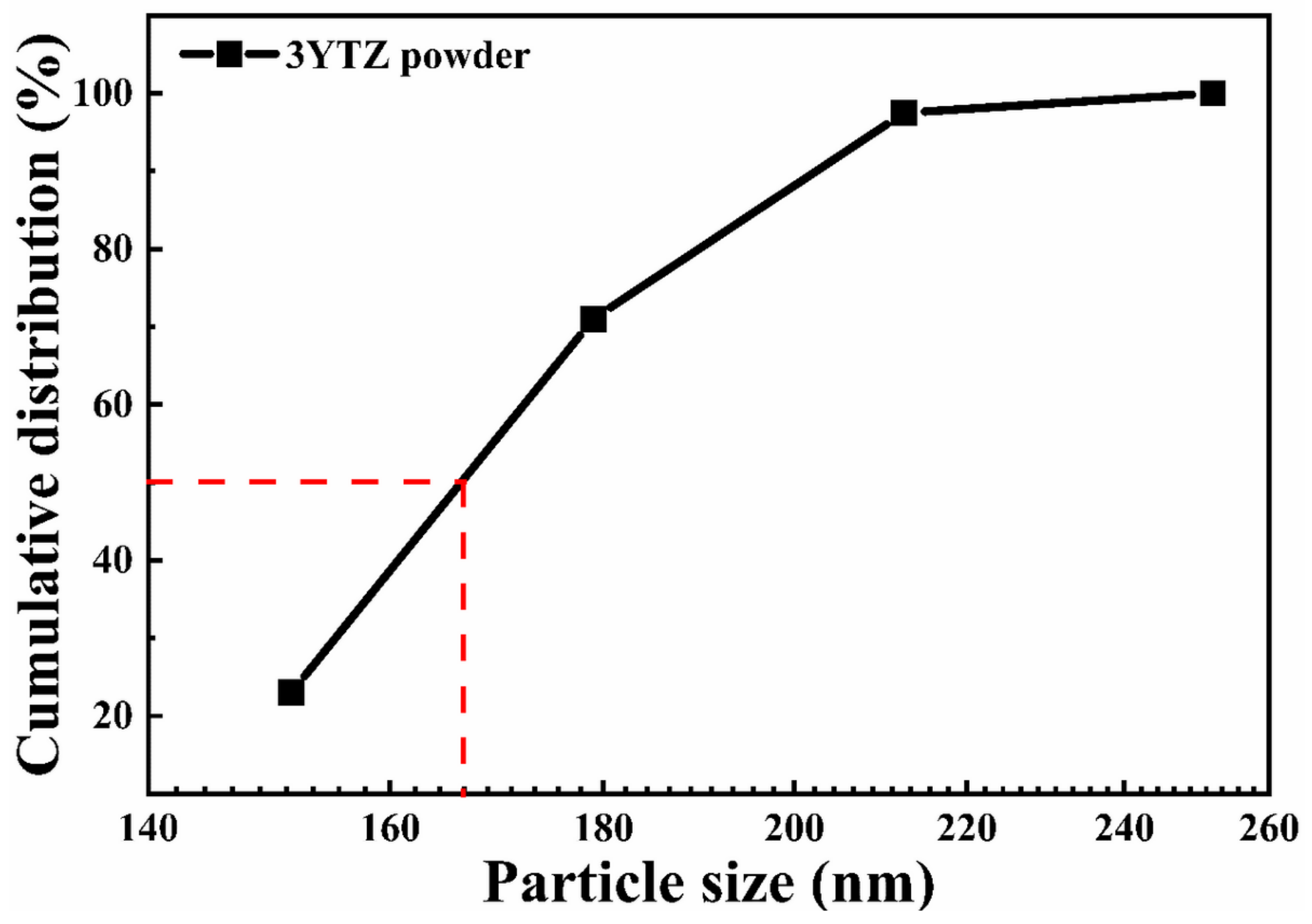

Figure 2

Cumulative particle size distribution of the YTZP slurry added with $0.2 w t \%$ Dolapix CE64. 


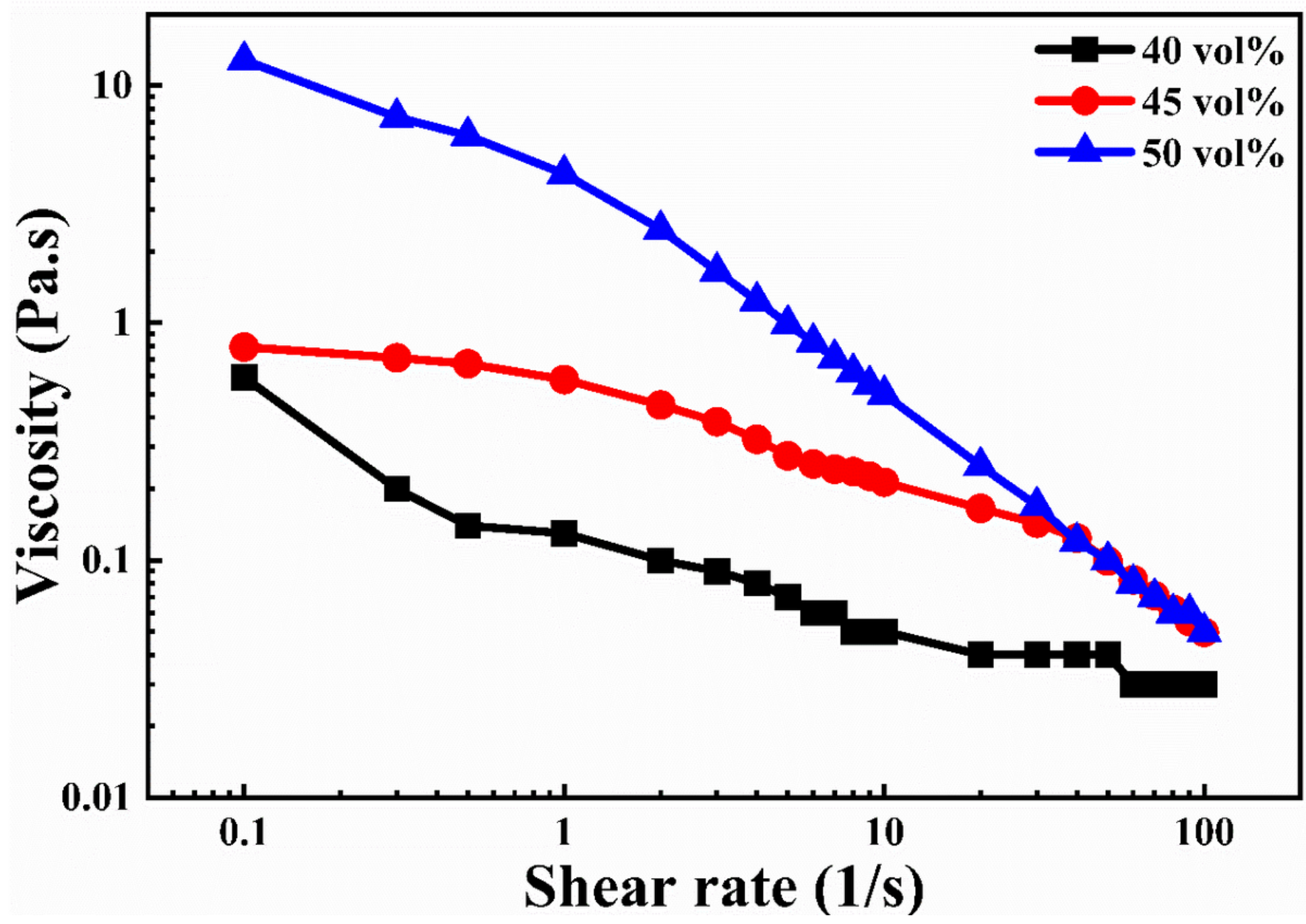

Figure 3

Effect of the solid content on the rheological behaviors of YTZP slurries with $0.2 \mathrm{wt} \%$ Dolapix CE64. 


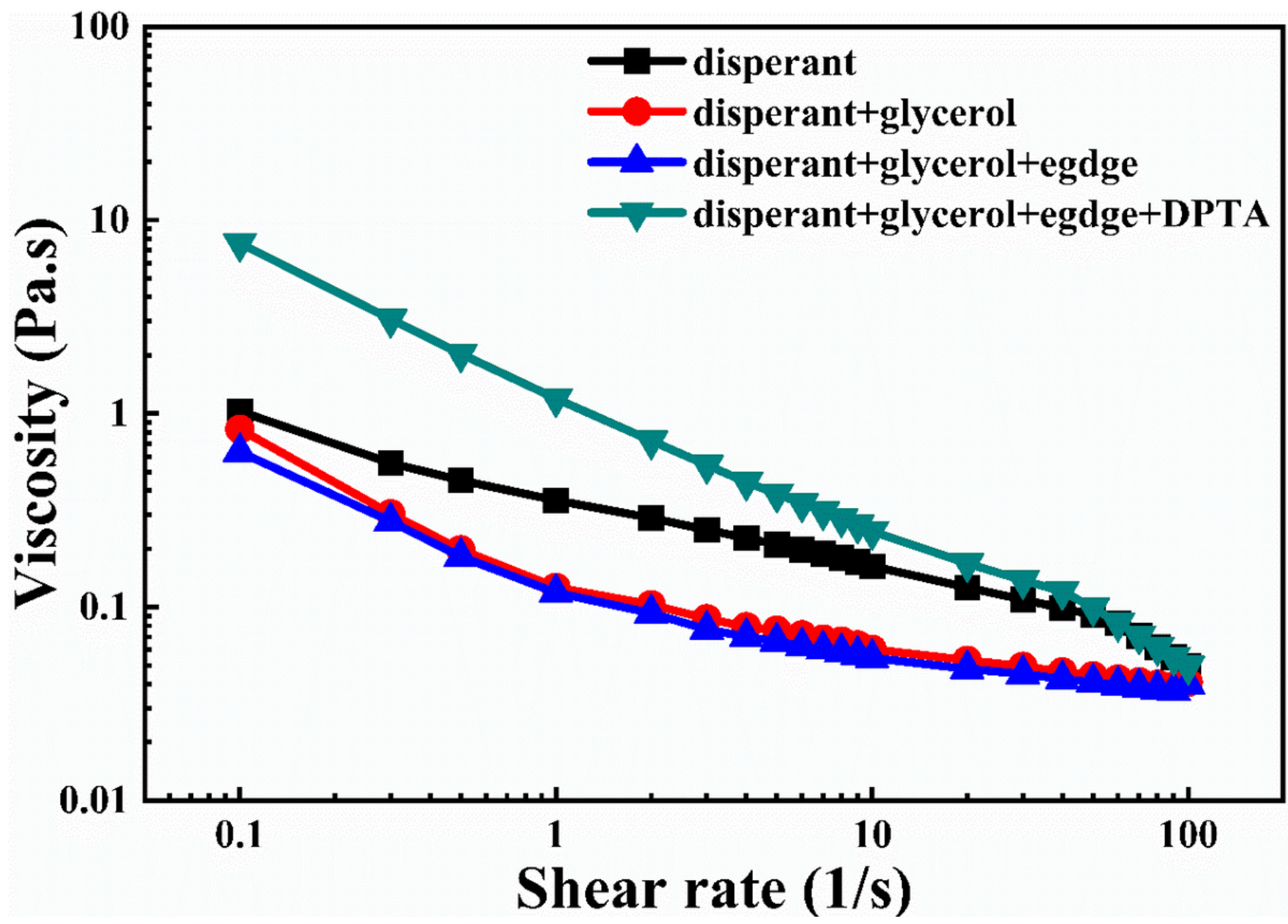

Figure 4

Effect of adding different organic vehicles on the viscosity of the YTZP slurry. 


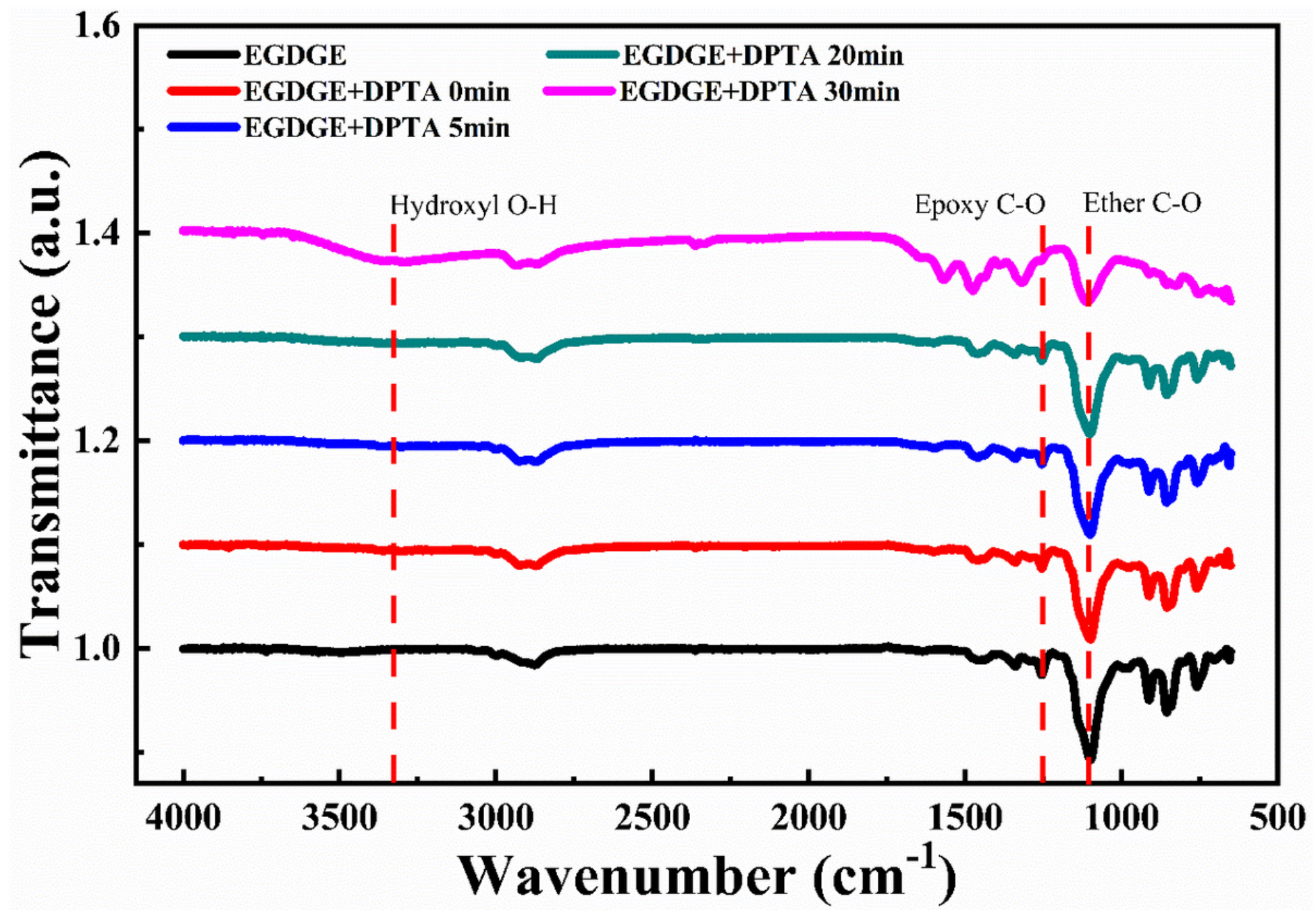

Figure 5

FTIR spectroscopy can be used to investigate the reaction time between the monomer, EGDGE, and initiator, DPTA. 




Figure 6

Effect of Dolapix CE64 addition on the polymerization rate measured by FTIR spectroscopy. 




Figure 7

Effect of $\mathrm{HQ}$ addition on the polymerization rate measured by FTIR spectroscopy. 


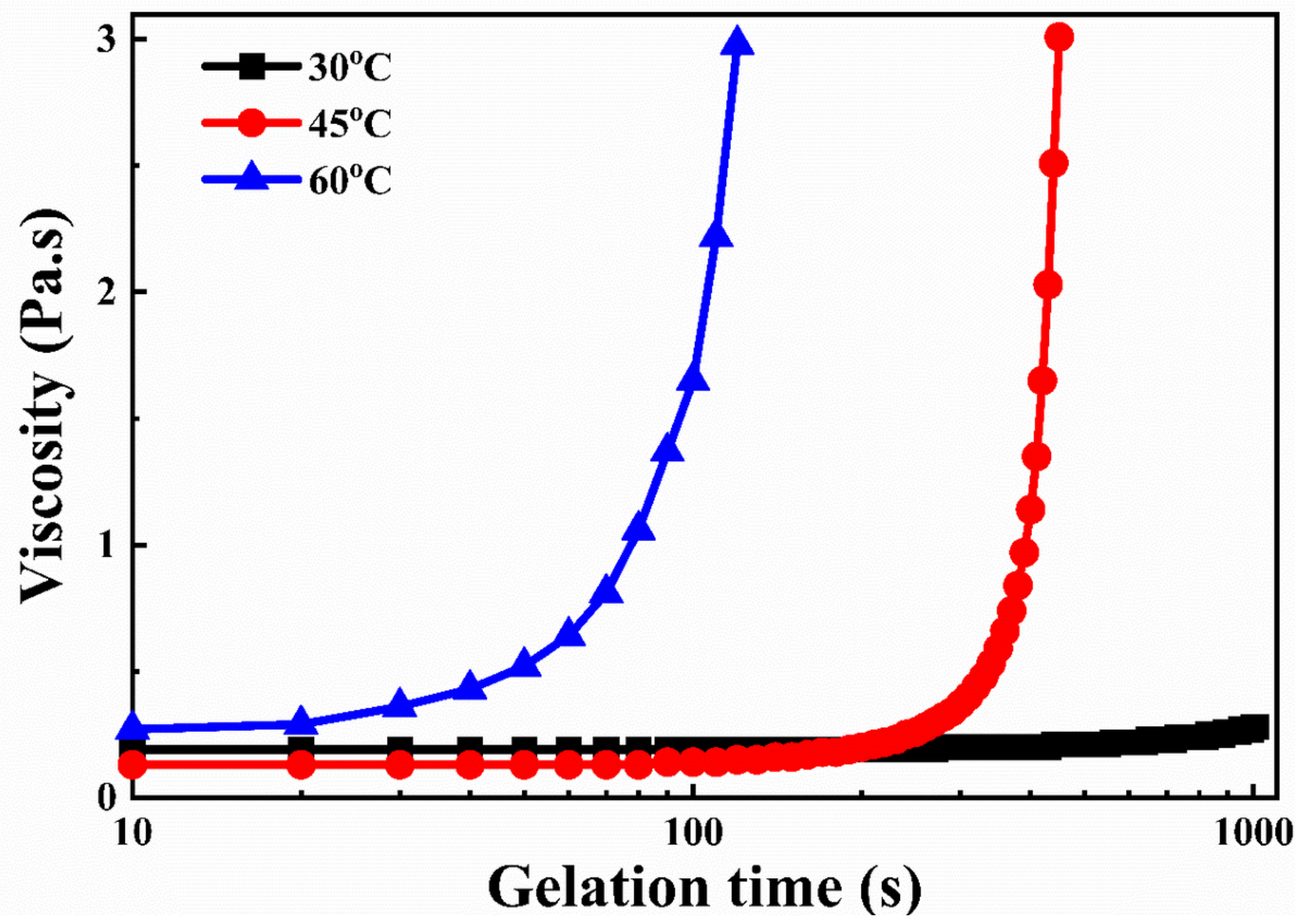

Figure 8

Effects of different curing temperatures and soaking time on the slurry viscosity (the mixture of EGDGE, DPTA, HQ, and Dolapix CE64). 


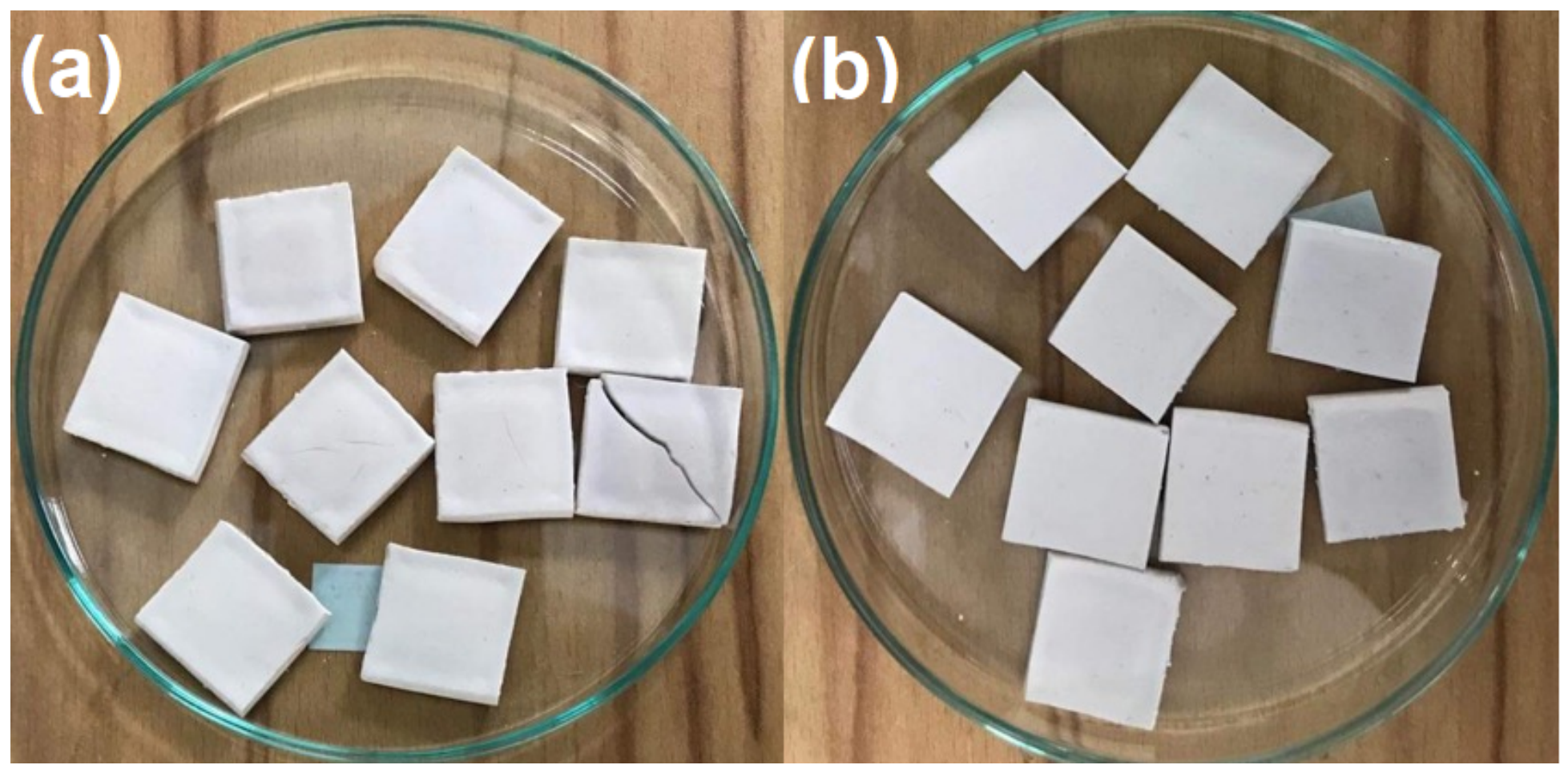

Figure 9

Appearance of the gel-casted samples after curing at $45^{\circ} \mathrm{C}$ and $60^{\circ} \mathrm{C}$.

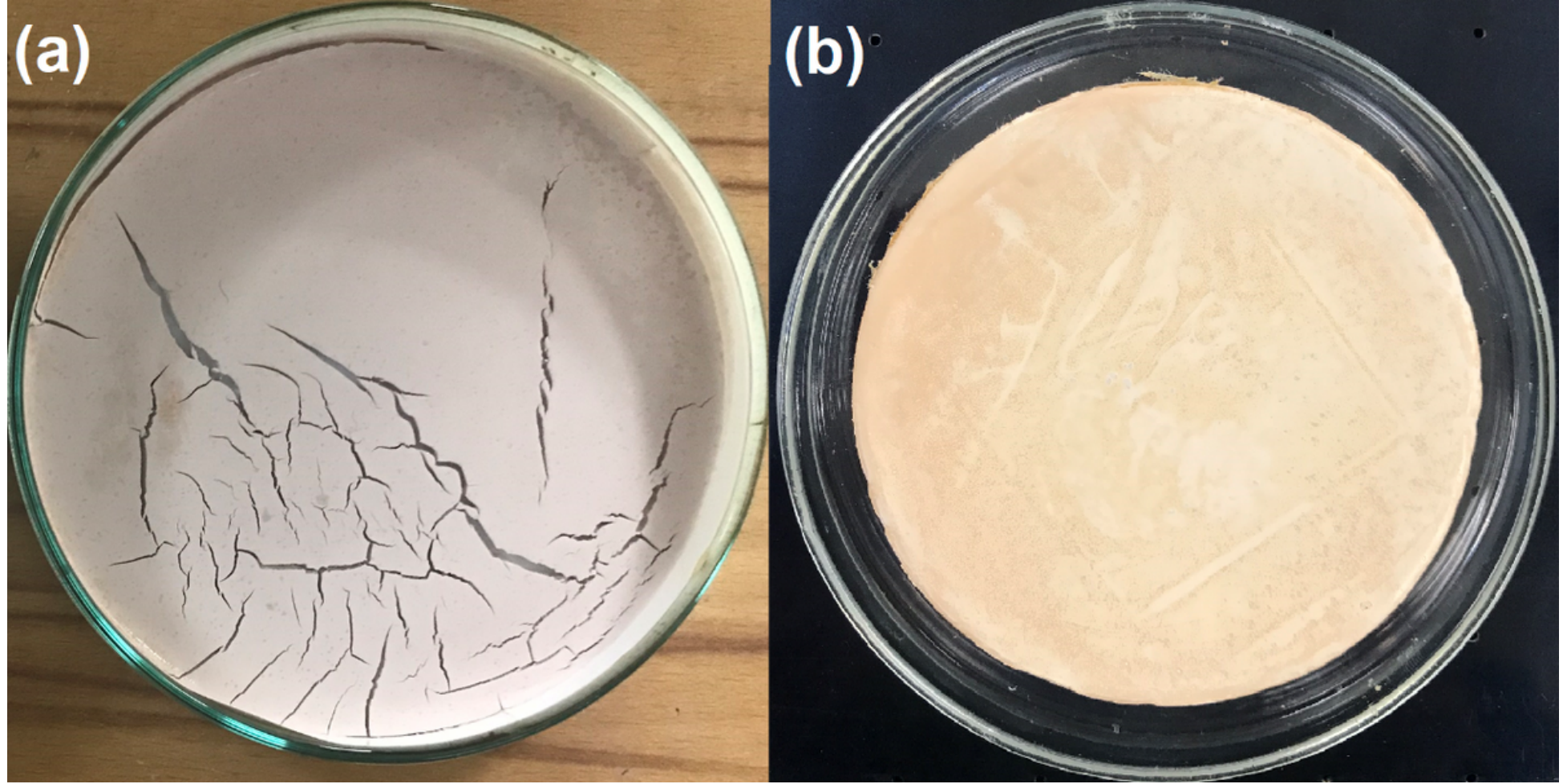

Figure 10

Appearance of the gel-casted samples with different B/P ratios (binder/plasticizer ratio). 


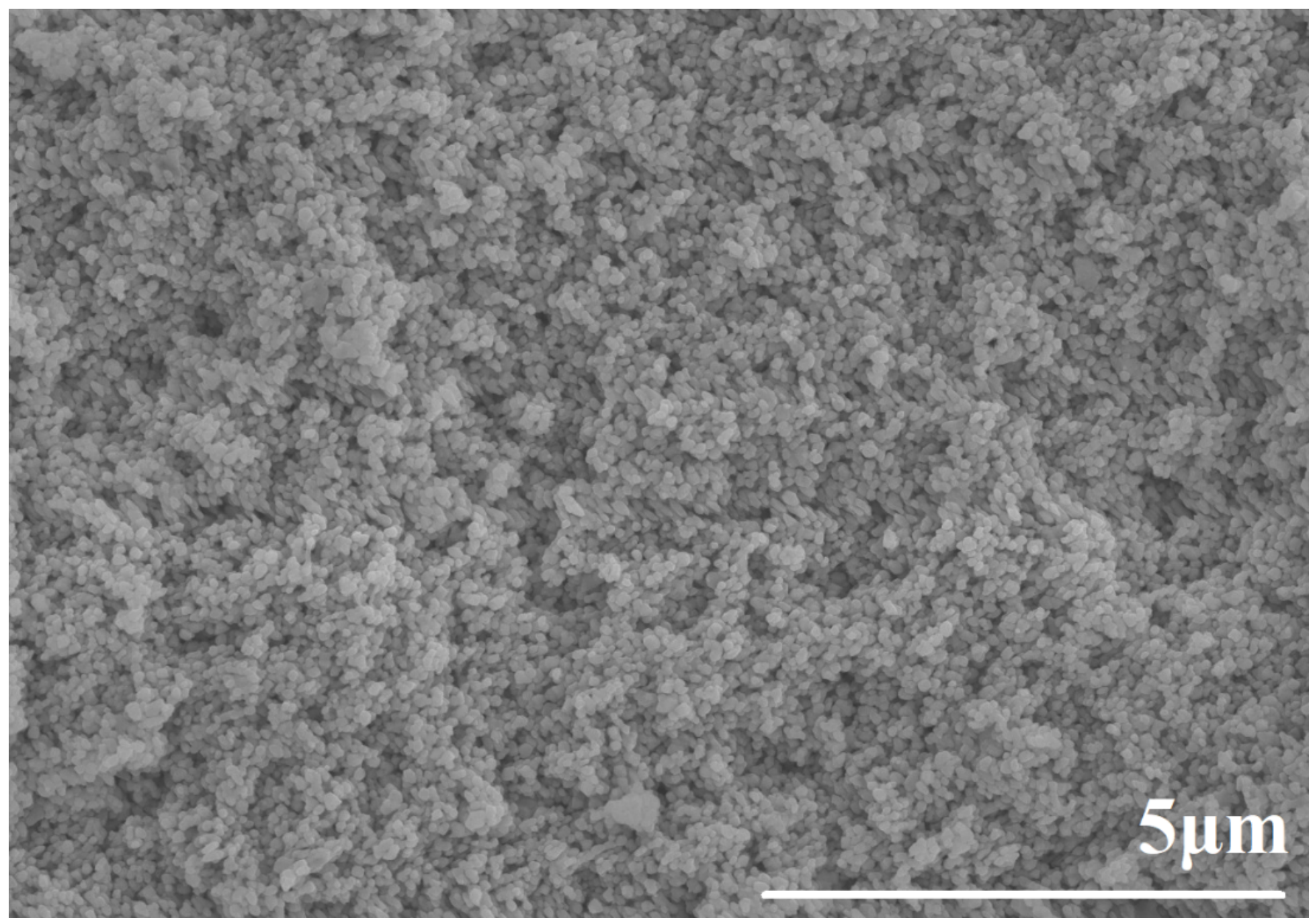

\section{Figure 11}

SEM microstructure of the green body prepared by gel casting and CIP process. 




Figure 12

Variation of the shrinkage and instantaneous relative density with the temperature for the YTZP green body. 


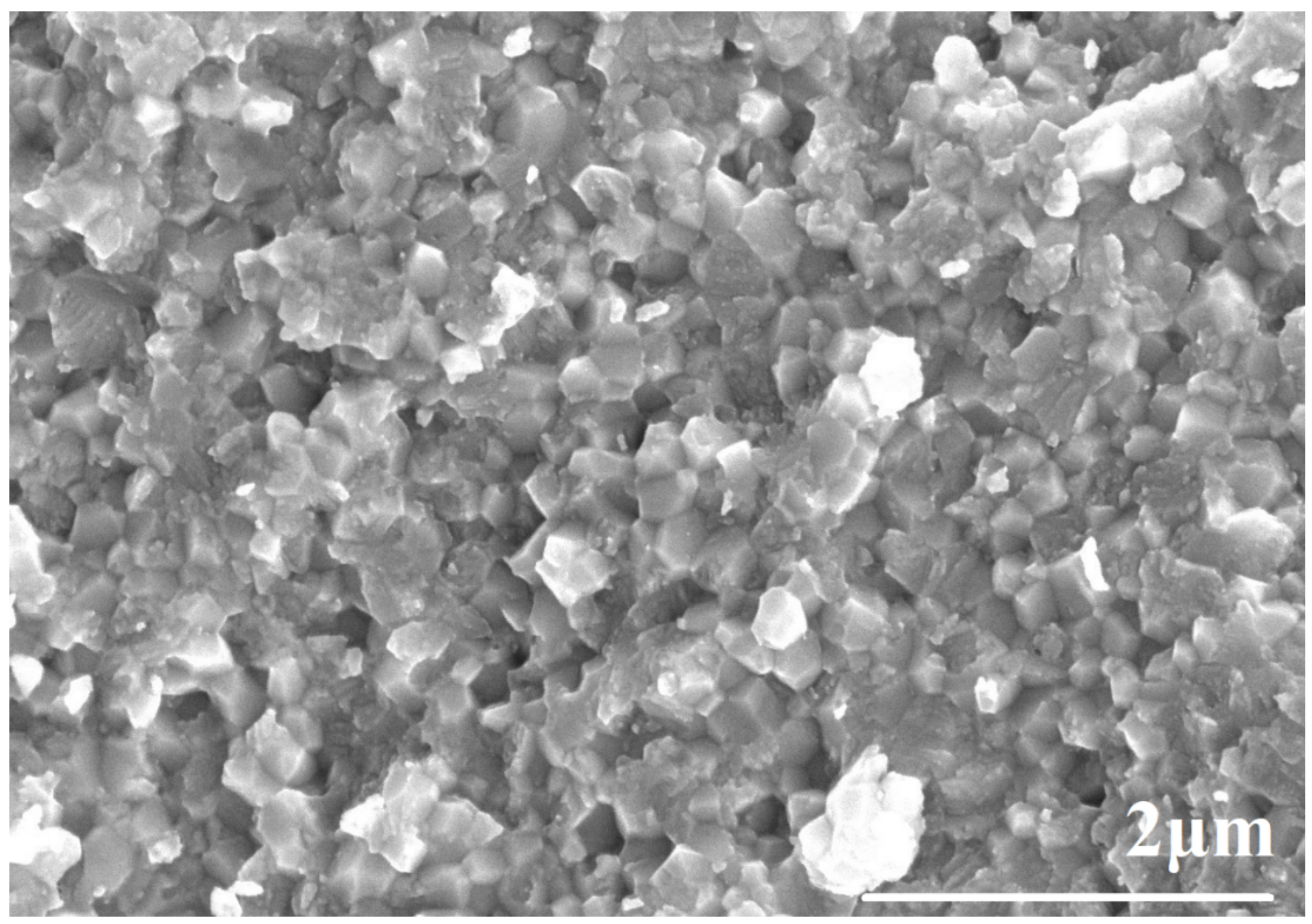

Figure 13

SEM microstructures of the fracture surface of YTZP ceramics after two-stage sintering (first stage sintering temperature: $1300^{\circ} \mathrm{C}$, the second stage sintering: $1240^{\circ} \mathrm{C}$ for $24 \mathrm{~h}$ ). 


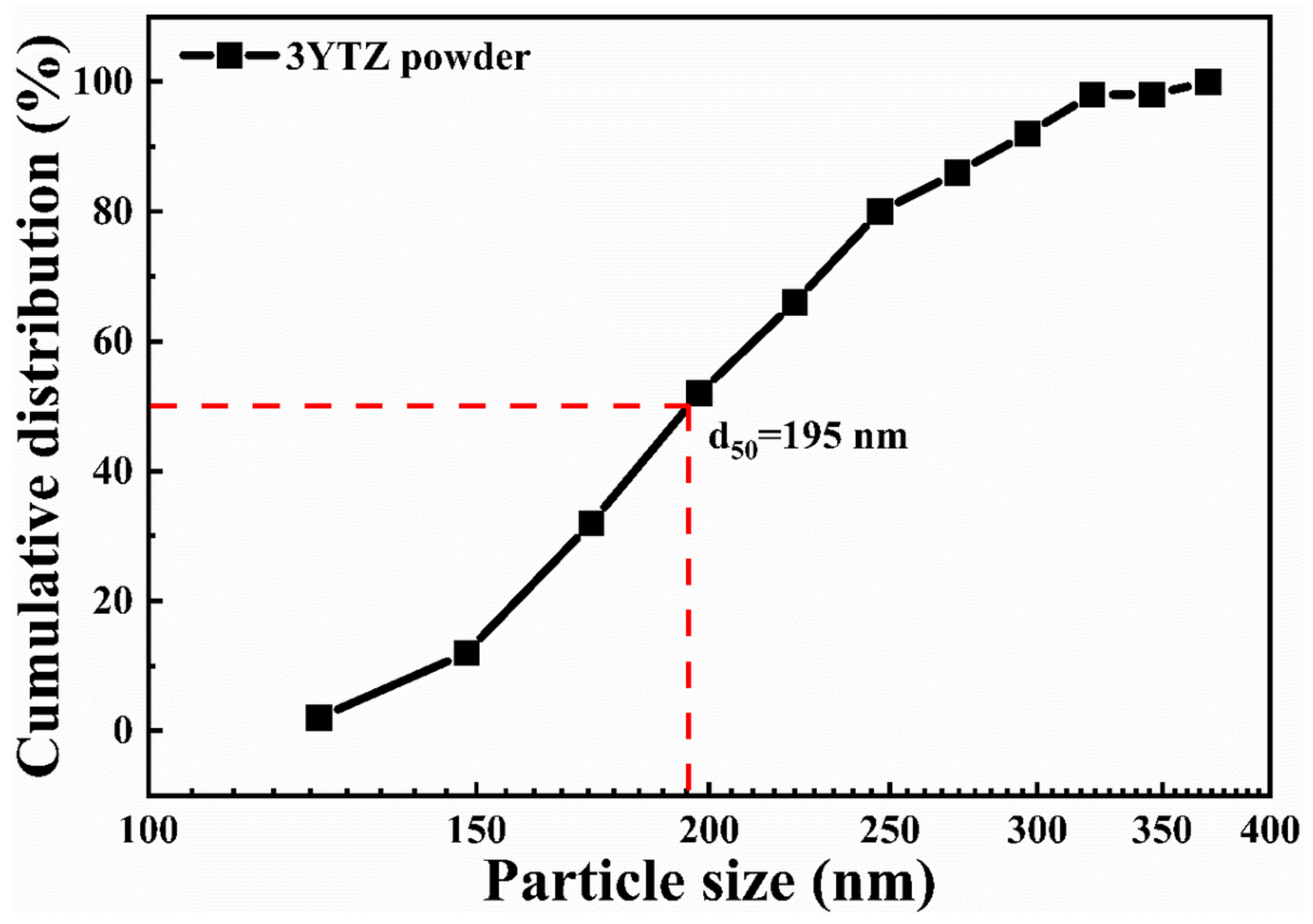

Figure 14

Cumulative grain size distribution of YTZP ceramics after two-stage sintering (first stage sintering temperature: $1300^{\circ} \mathrm{C}$, the second stage sintering: $1240^{\circ} \mathrm{C}$ for $24 \mathrm{~h}$ ). 




Figure 15

XRD pattern of the YTZP ceramic after two-stage sintering. 